\title{
Sexualidad, desnudismo y moralidad en el anarquismo español de los años treinta: de los debates en la prensa a la aplicación de la ley del aborto durante la Guerra Civil Española
}

\author{
Alejandro Lora Medina ${ }^{1}$ \\ Universidad de Sevilla \\ alora@us.es
}

RESUMEN: Este artículo tiene por objetivo el análisis de la visión anarquista de la sexualidad, el cuerpo, el desnudismo y la moral sexual, como conformadores de un nuevo individuo. Dichos debates, que encuentran en las publicaciones anarquistas el medio principal para su difusión, se basan necesariamente en los avances logrados en décadas anteriores en el campo de la medicina y en la extensión de una visión naturalista y armónica del cuerpo desnudo. El estudio forma parte de un análisis cuantitativo que muestra la defensa de una nueva ética sexual que moraliza el sexo como un comportamiento biológico saludable e introduce las bases para el debate posterior en las publicaciones anarquistas de la época: ¿procreación sin límites o anticoncepcionismo? Ambas corrientes trascendian el debate sexual para centrar la discusión en el modelo de sociedad que se construiría con la aplicación de cada una de estas opciones. Controversia que pareció, sin embargo, cerrarse parcialmente con la aprobación de la ley del aborto durante la Guerra Civil Española.

PALABRAS CLAVE: España; anarquismo; sexualidad; procreación; anticoncepcionismo; aborto.

Sexuality, nudity and morality in the Spanish anarchism of the thirties: from the debates in the press to the application of the abortion law during the Spanish Civil War

ABSTRACT: This article aims to analyse the anarchist vision of sexuality, the body, nudity and sexual morality as shapers of a new individual. Necessary

${ }^{1}$ ORCID iD: https://orcid.org/0000-0002-7314-8327.

Copyright: (C) 2018 CSIC. Este es un artículo de acceso abierto distribuido bajo los términos de una licencia de uso y distribución Creative Commons Reconocimiento 4.0 Internacional (CC-BY 4.0) 


\begin{abstract}
precedents to these debates, which utilise anarchist publications as their main means of diffusion, include medical advances achieved in previous decades and the extension of a naturalistic and harmonious vision of the naked body. This study is part of a quantitative analysis that shows the defence of new sexual ethics that moralise sex as healthy biological behaviour, and introduces the basis for the subsequent debate in the anarchist publications of the time: unbounded procreation or contraception? Both currents transcended the sexual debate to focus the discussion on the model of society that would be constructed by applying these respective options. The controversy appeared to have been settled, at least in part, by the approval of the abortion law during the Spanish Civil War.
\end{abstract}

\title{
KEY WORDS: Spain; anarchism; sexuality; procreation; contracep- tion; abortion.
}

CÓMO CITAR ESTE ARTÍCULO/CITATION: Lora Medina, Alejandro, «Sexualidad, desnudismo y moralidad en el anarquismo español de los años treinta: de los debates en la prensa a la aplicación de la ley del aborto durante la Guerra Civil Española», Hispania, 78/260 (Madrid, 2018): 817-846. https://doi.org/10.3989/hispania.2018.020.

\section{INTRODUCCIÓN}

La historia de la sexualidad, englobada bajo el paraguas protector de la historia socio-cultural, es un área de estudio que hasta hace poco tiempo despertaba dudas acerca de su pertinencia como ámbito de análisis e investigación científica. La historia de la familia, de la vida cotidiana o de lo íntimo, en general, tratan de aportar una nueva visión acerca del pasado. Nuevos enfoques que reconstruyen las vivencias y experiencias que individuos o colectivos determinados poseían sobre la sexualidad y cómo abordaban tanto su parte teórica, como su dimensión práctica. En la actualidad, la historia de la sexualidad resulta un ámbito cada vez más atrayente, debido a los cambios operados en la mentalidad colectiva ${ }^{2}$.

El discurso ácrata se introduce en el ámbito de lo privado para fijar su visión sobre conceptos como el amor, la sexualidad o la familia, como vía para la confección de una moral integral que sea una opción distinta al pensamiento tradicional de raíz religioso. Esta moral sexual ácrata, ya presente desde comienzos de siglo, abarca desde la higiene, la educación sexual, la lucha antivenérea o el amor libre, hasta la abolición de la prostitución, el control de la natalidad o el aborto. Su vivencia se vincula además con un nuevo estilo de vida basado en prácticas como el naturismo, el vegetarianismo o el nudismo,

2 GRACIA CÁRCAMO, 19 (Madrid, 1995): 189-222. VÁZQUEZ GARCÍA, 56/194 (Madrid, 1996): 1007-1035. GUEREÑA, 2011: 11-22. 
en sintonía con una visión naturalista del mundo. Estas ideas revisten una extraordinaria relevancia tanto para el conocimiento del movimiento libertario como por lo que revelan sobre los mecanismos colectivos de pensar y sentir de este grupo ideológico. En la medida en que la percepción de la realidad opera como motor para la acción en una etapa crucial de la historia contemporánea de España como los años treinta, el proceso de modernización que experimentó el país se traduciría en una ingente legislación tendente a salvar las distancias con el resto de países democráticos.

La ética sexual defendida, contraria al matrimonio tradicional y a la moral católica dominante, se encontraba ligada a posturas revolucionarias que querían de una modificación estructural de las distintas pautas del comportamiento en materia sexual. El discurso ácrata aboga por una vivencia abierta y sin complejos de la sexualidad, contraria a toda represión tanto física como moral que imponía la tradición. Las publicaciones libertarias se convirtieron en la vanguardia cultural del movimiento al ser un espacio abierto de sociabilidad escrita, al mismo tiempo que definía a sus lectores como seres culturalmente activos y mentalmente inconformistas. El anhelo por crear una moral basada en una experimentación libre del sexo se configura desde la preocupación de otorgarle un sustento científico y racional en un camino que le llevará a coincidir parcialmente con asociaciones burguesas con intereses similares. Entre esta iba a sobresalir la llamada Liga Mundial por la Reforma Sexual sobre Bases Científicas, creada en 1928 por el sexólogo alemán Magnus Hirschfeld. Tenía el objetivo de promover un cambio estructural en el tratamiento de la sexualidad a nivel internacional y contó entre sus representantes españoles con dos destacados médicos libertarios, Isaac Puente y Félix Martí Ibáñez

Los avances en el campo médico fueron esenciales para el movimiento libertario, cuyo afán por mostrar un discurso cientificista condujo a la medicalización de sus postulados. Por esta razón, muchos de los principales propagandistas estaban estrechamente relacionados con el mundo terapéutico: Higinio Noja, Mariano Gallardo, Javier Serrano, Amparo Poch y Gascón, Roberto Remartínez, Antonio García Birlán, Isaac Puente y Félix Martí Ibáñez. La influencia de la medicina en el discurso sexual se inserta en un ambiente colectivo de debate y proliferación de una ingente literatura que ofrece una visión inédita en el campo de lo sexual en España. Ya desde principios de

3 La Liga, cuya sección española estaba formada entre otros por Gregorio Marañón, Luis Huerta o Hildegart Rodríguez, nació con la intención de luchar por logros concretos como el matrimonio civil, la concepción libre y responsable, la protección de las madres solteras, el eugenismo o la prevención de las enfermedades venéreas, entre otros. LORENZO PINAR, 2009: 286. ÁLVAREZ PELÁEZ, 64/218 (Madrid, 2004): 948-949. NASH, 1995: 286-287. HUERTAS y NOVELLA GAYA, 764 (Madrid, 2013): 2-3. MORENO MENGÍBAR y VÁZQUEZ GARCÍA, 309 (Madrid, 1996): 82. NAVARRO NAVARRO, 1997: 76; 769 (Madrid, 2014): 6. 
siglo se habían traducido al español las obras de importantes autores, sexólogos y científicos europeos — como Havelock Ellis, Auguste Forel, Iwan Bloch o Sigmund Freud-, que modernizaron los planteamientos médicos. Sería a partir de los años 20, pero sobre todo de la década posterior, cuando el discurso sexual adquiere una mayor relevancia con la proliferación y difusión de publicaciones, campañas, jornadas, etc. de reformadores sexuales españoles que consolida un discurso sexual moderno a nivel nacional ${ }^{4}$.

\section{Sexualidad y moralismo en el anarquismo español de los años treinta}

La originalidad de la ética sexual anarquista reside en unir opresión material con opresión moral, de ahí que la lucha por una sexualidad libre fuera una más de las distintas formas que tomaba la revolución social. La apología del igualitarismo sirve para condenar la utilización de la mujer como instrumento pasivo del placer del hombre, mientras la condena de la moral sexual tradicional lleva a la censura de la institución matrimonial. En los años treinta, el discurso sexual no sólo aumenta en los medios ácratas, sino que encuentra en médicos libertarios como Isaac Puente, Félix Martí Ibáñez, Higinio Noja o Javier Serrano a sus principales defensores. Esta aproximación a la sexualidad desde un enfoque científico-biológico choca frontalmente con el pensamiento religioso dominante. Bajo este enfoque, Martí Ibáñez achaca a la «moral farisea» de la Iglesia la impureza que rodea el sexo y critica la extensión de la represión sexual y la castidad del celibato como prácticas antinaturales ${ }^{5}$. La libertad sexual se defiende a partir del respeto de lo natural como principio supremo, vaciando de toda connotación moral aquellas funciones propias de la biología humana: «Cohabitar cuando de ello se siente necesidad es tan dig-

4 Estudios, 134, octubre de 1934. Acracia, 307, 19 de julio de 1937. ANDRÉS GRANEL, 5 (s.1., 2008): 68. El advenimiento de la Segunda República permitió a algunos de estos defensores estatales de la reforma sexual — como Luis Jiménez de Asúa, José Sanchís Banús o Gregorio Marañón-, intentar llevar a la práctica sus planteamientos mediante los instrumentos legales que tenían a su servicio como parlamentarios. El socialismo también se posicionó a favor de impulsar cierto reformismo en materia sexual pero, a diferencia del anarquismo, no generó un discurso sexual propio. En sus propuestas confluían las tradiciones del socialismo teórico con elementos inherentes a la familia burguesa: la familia como centro vertebrador de la sociedad, la higiene, el matrimonio civil y disoluble, la importancia de la educación, el culto a la maternidad, la subordinación positiva de la mujer, el rechazo del aborto, etc. VÁZQUEZ GARCÍA y MORENO MENGÍBAR, 1997: 132-135. LORENZO PINAR, 2009: 264 y 286. BARRACHINA, 64/218 (Madrid, 2004): 1005-1009.

5 Estudios, 136, diciembre de 1934. 
no, racional y humano como lo puede ser el comer cuando se tiene hambre y orinar cuando se tiene gana» ${ }^{6}$.

Muchos militantes libertarios, demasiado apegados a comportamientos tradicionales, no acababan de interiorizar la vivencia de una sexualidad libre y sin tabúes. Entre ellos seguía dominando cierto egoísmo de género que abogaba por la libertad sexual del hombre, mientras la mujer quedaba relegada a un segundo plano. Masculinidad y femineidad eran dos categorías que se encontraban en definición conceptual, dado que el marco de referencia había cambiado, ya que el anarquismo buscaba la transformación radical de las estructuras sociales y mentales tradicionales. Sin embargo, el idealismo ácrata iba a chocar con el enorme peso de la herencia cultural que hacía que determinados comportamientos fuesen criticables a nivel teórico. María Lacerda de Moura, anarquista y colaboradora de la revista Estudios, definía a los que no reconocían la igualdad femenina como anarquistas «feminófobos» por mantener, aun siendo conscientes del sometimiento de esta, la preponderancia de un género sobre el otro. La permanencia de este proceder fue un hándicap para muchas mujeres anarquistas y retrasó su incorporaran a la organización confederal al mismo nivel que el hombre. En palabras de Higinio Noja, la mujer había sido convertida por la sociedad capitalista «no en una mujer, no una madre, no un ser pensante y sensible, sino un sexo servido por órganos y siempre presto a satisfacer la lujuria del esposo o del amante» ${ }^{7}$. En definitiva, la extensión propagandística de estas ideas afectaba por igual a hombres y mujeres, ya que tanto el uno como el otro debían interiorizar que el cuerpo les pertenecía y que el disfrute carnal no era sinónimo de vergüenza, pecado o lujuria ${ }^{8}$.

Esta labor educadora se extendía al mundo de la literatura que experimentó un gran boom divulgativo en la década de los treinta, con la que proliferación de libros y artículos de abierta temática sexual. Estas obras cumplían un importante papel instructor con la denuncia de comportamientos licenciosos, no sólo con escritos en los que se abordaba científica y médicamente dicha temática, sino a través de la publicación de novelas sentimentales con una evidente intencionalidad pedagógica y proselitista. Estas historias, aunque narran situaciones ficticias, persiguen educar a la militancia en el comportamiento amoroso-sexual correcto, a la par que se denuncian situaciones - como agresiones sexuales, matrimonios de conveniencia, desigualdad de género y ausencia de afecto y amor en la pareja-, que son asociadas a conductas impropias de un anarquista. Dentro de los personajes representados, estereotipos que buscan ser repre-

6 Estudios, 160, enero de 1937.

7 Estudios, 78, febrero de 1930.

8 Estudios, 107, julio de 1932. LORA MEDINA, 16 (Madrid, 2018): 162-163. NASH, 1981: 46 y 111. ARESTI, 2001: 227-235; 2010: 7 y 13. ESPIGADO TOCINO, 45 (Madrid, 2002): 39-72.

Hispania, 2018, vol. LXXVIII, nº. 260, septiembre-diciembre, págs. 817-846, ISSN: 0018-2141, e-ISSN: 1988-8368 https://doi.org/10.3989/hispania.2018.020 
sentativos de la realidad social, junto al prototipo de joven militante sano y emancipado de los convencionalismos sociales, no falta el personaje del burgués joven, prepotente, dominado por la lujuria, que usa y abusa de las mujeres a su antojo?.

Esta novelística no pierde la oportunidad de exaltar las bondades de la ideología ácrata al tiempo que condena todo lo relacionado con el Estado, la Iglesia y el capitalismo. En novelas como En las garras de la lujuria de Gregorio Gallego - miembro del Comité Peninsular de las JJLL madrileñas durante la guerra-, no sólo se enjuicia la moral sexual burguesa a través de un hombre que practica una sexualidad violenta y disfruta de la prostitución, sino que se critica el sistema capitalista por permitir la explotación sexual de la mujer. Sin embargo, la visión romántica de las relaciones sentimentales de esta novelística libertaria apenas esconde el tópico del hombre como salvador o maestro de la mujer, lo que denota la influencia de una sociedad en la que perviven tópicos y comportamientos marcadamente patriarcales en el seno del propio movimiento ácrata ${ }^{10}$.

La originalidad del discurso sexual ácrata se sustenta en adaptar las nuevas concepciones médicas de la época a la concepción del anarquismo del hombre y la mujer como seres oprimidos por una sociedad que les obliga a tapar el cuerpo y ocultar sus necesidades fisiológicas por influencia de la moral religiosa. La sexualidad se codifica como un mecanismo más para la eliminación del autoritarismo que se entiende como intrínseco al orden establecido y a la moral sexual tradicional. En esta línea, fueron especialmente sugerentes las portadas de la revista Estudios en las que se muestran desnudos tanto de hombres como de mujeres, reivindicándose una visión naturalista del cuerpo como paso previo a la normalización de la conducta sexual. La revista valenciana, sin embargo, no se salvó de ser tachada de pornográfica y provocadora a pesar del carácter cientificista y naturista que impregnaban sus páginas. En la cultura europea, el desnudo se desarrolla principalmente en círculos progresistas que trascienden la concepción artística para reclamar una modernización de los comportamientos en materia sexual, lo que introduce al anarquismo español en estos ambientes de vanguardia ${ }^{11}$.

Junto al carácter rupturista de estas publicaciones, las reproducciones destacan por su realismo gráfico y su intención provocadora, siendo especialmente evidente en el caso de las representaciones femeninas, como las publi-

9 Solidaridad Obrera, 1076, 27 de septiembre de 1935; 1462, 19 de diciembre de 1936. Iniciales, 6, 6 de junio de 1934.

10 GALLEGO GARCÍA, 1936: 7 y 23. SIGUÁN BOEHMER y MARCO, 1981: 76-142.

11 Estudios, 72, agosto de 1929; 107, julio de 1932; 113, enero de 1933; 119, julio de 1933; 160, enero de 1937. DÍEZ, 2001: 73. NAVARRO NAVARRO, 1997: 143-144. ÁLVAREZ PELÁEZ, 64/218 (Madrid, 2004): 952-953. 
FIGURA I. Desnudos de hombres y mujeres en Estudios entre 1930 y 1937
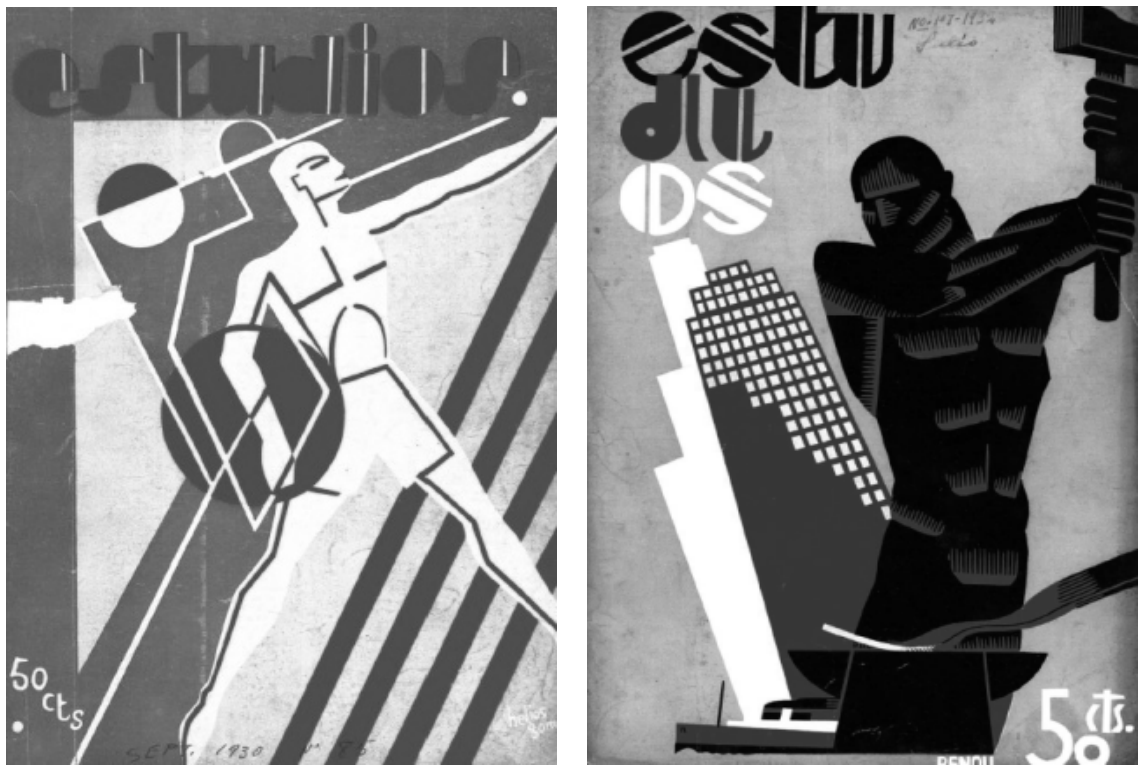

Arriba, de izquierda a derecha, imágenes 1 y 2 representando desnudos masculinos: Estudios, 85, septiembre de 1930; 107, julio de 1932. Abajo, de izquierda a derecha, imágenes 3 y 4 mostrando los desnudos femeninos: Estudios, 137, enero de 1935; 157, octubre de 1936.
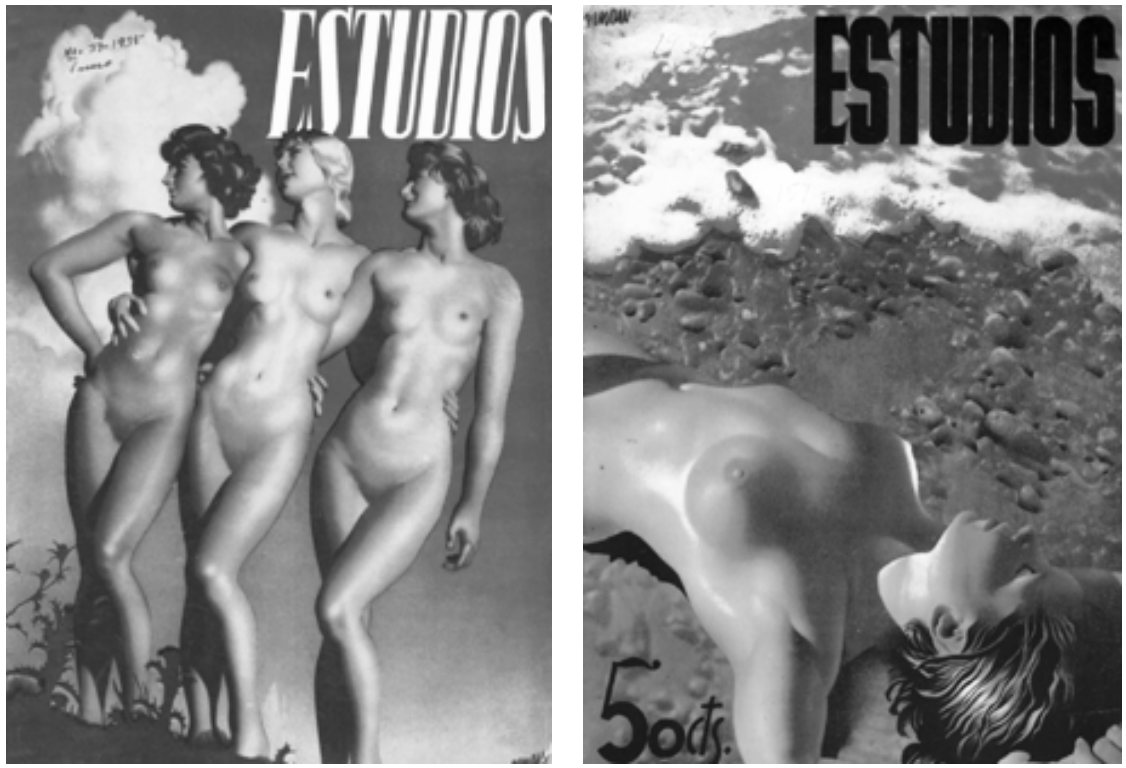

Hispania, 2018, vol. LXXVIII, nº. 260, septiembre-diciembre, págs. 817-846, ISSN: 0018-2141, e-ISSN: 1988-8368 https://doi.org/10.3989/hispania.2018.020 
cadas en las portadas de Estudios. Aunque la revista muestra múltiples desnudos de los dos sexos, se aprecia como ambos cumplen funciones distintas pero complementarias. Por un lado, la figura femenina sirve para reclamar una naturalización del cuerpo humano como un elemento bello y digno de contemplación, como se aprecia en las imágenes 3 y 4, recurriéndose para ello en un enorme realismo pictórico. Y, por otro, la figura masculina que pierde el realismo de las anteriores en beneficio de formas esquemáticas o figuradas, para simbolizar el vigor y la fuerza del varón en acción. Como se muestra en las reproducciones 1 y 2 , el hombre aparece en movimiento, realizando funciones que conllevan fuerza física y virilidad, frente a las posiciones pasivas, tranquilas y delicadas de las imágenes de mujeres. El desnudo masculino, mostrado sólo en acciones que ensalzan su virilidad o junto a la mujer en escenas corales, se representa con el torso desnudo pero nunca mostrando sus órganos sexuales en una idealización que recuerda a las estatuas de héroes griegos o emperadores romanos. Estas pautas, aparentemente inocentes, no hacen más que reflejar la concepción mayoritaria de un colectivo en el que, a pesar de la defensa de la igualdad estructural entre hombres y mujeres, no acaba de liberarse de muchos de los estereotipos ligados a la moral tradicional. De las 54 portadas de Estudios en las que aparecen representados desnudos, únicamente 12 son de hombres. Mientras, la fémina - que representa el $78 \%$ del total de las portadas de desnudos-, es exhibida tanto con el busto como con el sexo desvestidos en un claro símbolo de delicadeza y feminidad. Son retratos que huyen de la impudicia y de una concepción lujuriosa del sexo y que pretenden mostrar una visión del cuerpo como fuente de felicidad natural. Se presenta un modelo ideal y estereotipado del cuerpo femenino, como sucedía con el masculino, que está en la línea del idealismo defendido por el anarquismo. Una construcción cultural que no rompe con la tradición, sino que mantiene intacto el ideal de belleza en torno a unas mujeres altas, guapas, delgadas y esbeltas ${ }^{12}$.

La prensa se convirtió en uno de los principales canales para la difusión de esta ética sexual anarquista, de ahí la relevancia que adquirieron los distintos artículos y secciones que abordaban los diversos aspectos y temas de ésta: higiene, eugenesia, educación sexual, abolición de la prostitución, procreación consciente, lucha antivenérea, amor libre, libertad sexual, maternidad consciente o control de la natalidad. Esta labor pedagógica se acentuaba, en el caso de algunas revistas ácratas, con la publicación de secciones especiales destinadas a recibir y contestar preguntas de los lectores. De este modo la comunicación entre emisor y receptor era algo vivo y evidenciaba las enor-

12 Estudios, 77, enero de 1930; 165, junio de 1937. PANDO DESIERTO, 8 (Madrid, 1995): 334. MÉNDEZ PÉREZ, 2004. DE VILLENA, 2008. NEAD, 2013: 17-46. SÁNCHEZ LÓPEZ, 2014: 81-126.

Hispania, 2018, vol. LXXVIII, nº. 260, septiembre-diciembre, págs. 817-846, ISSN: 0018-2141, e-ISSN: 1988-8368 https://doi.org/10.3989/hispania.2018.020 
mes lagunas existentes en todo tipo de temas, incluido el sexual. En una sociedad con elevadas cifras de analfabetismo ${ }^{13}$, esta era una forma de resolver muchas de las cuestiones que por desconocimiento, ignorancia o mal aprendizaje tenía la población. En definitiva, altos porcentajes que consolidan la conservación de comportamientos tradicionales en el seno de una población iletrada que alberga muchos tabúes y conflictos morales ${ }^{14}$.

La ética sexual anarquista es interpretada como la moral de la Naturaleza en una visión naturalista de la vida cuyos límites serían la salud y la libertad: «cuando la moral sexual perjudica a la salud, ha pasado a ser inmoralidad, que unos llaman libertinaje; y cuando topa con la libertad, el amor ha dejado de ser amor, para ser esclavitud» ${ }^{15}$. Para Gaston Leval, la libertad sexual no puede ser confundida con la defensa desatada del instinto ni la lujuria, sino que reside en la vivencia de una cultura moral del sexo que hace del individuo un ser consciente de su cuerpo. El sexo es interpretado como un hecho biológico trascendental que, además de proporcionar bienestar físico, sirve para la reproducción de la especie. Por esta razón, el «falseamiento» de la línea sexual natural sería considerada la causa principal para el posterior desarrollo de neurosis, aberraciones eróticas o «desviaciones» del amor. La perspectiva médica en el tratamiento de la sexualidad se combina con métodos educacionales no autoritarios. La impronta libertaria acaba prevaleciendo al apostar por la prevención como forma de curación, mostrando que una vida sana es una vida sin enfermedades. La apuesta porque el «mejor tratamiento es el de la santa Libertad» ${ }^{16}$ por encima de otros métodos, es la traslación al campo de las dolencias de la solución ácrata para la política ${ }^{17}$.

La defensa de lo racional y biológico en el tratamiento de lo sexual no es óbice para que en la moral sexual ácrata se mantenga el concepto de pureza, redefinido según sus propios parámetros. Como señala Higinio Noja, destacado maestro racionalista y propagandista onubense: «Sólo se es puro obede-

13 En la España de los años 30, el analfabetismo, a pesar de haber descendido respecto a la década anterior, alcanzó cifras que superaban el $40 \%$, demostrando que el esfuerzo educativo llevado a cabo durante la Segunda República logró aumentar la población alfabetizada de 13.171.685 habitantes en 1930, a 17.117.277 en 1940. GABRIEL FERNÁNDEZ, 8/1 (Madrid, 1997): 202-203.

14 Cuestiones como la planteada por R. A., en abril de 1934, sobre si un libertario podía unirse con una mujer que había tenido relaciones sexuales reflejan un gran desconocimiento de cuestiones básicas sobre sexualidad entre los propios lectores de estas revistas, afines o seguidores de las ideas anarquistas. Estudios, 77, enero de 1930; 94, junio de 1931. La Revista Blanca, 272, 6 de abril de 1934. NASH, 1995: 283-284 y 291-292. NAVARRO NAVARRO, 1997: 97-111, 117-127 y 143-144.

15 La Revista Blanca, 281, 8 de junio de 1934.

16 Estudios, 143, julio de 1935.

17 Solidaridad Obrera, 438, 8 de junio de 1932. Espartacus, 13, 22 de febrero de 1937. Nosotros, 5, 16 de febrero de 1937. GARCÍA MAROTO, 1996: 120-121. 
ciendo a la naturaleza, y puesto que ella puso en nosotros la atracción sexual, no existe, en el acto de seguir y cumplir sus impulsos, nada de qué sonrojarse» ${ }^{18}$. Si en la moral tradicional la virginidad de la mujer es sinónimo de pureza moral, en la ética anarquista asistimos a una inversión de valores ya que la castidad es percibida como el equivalente de una sexualidad represiva que no permite la exteriorización natural del deseo biológico. La solución a esta problemática de la ignorancia sexual reside en el fomento de una educación integral desde la infancia que hace del niño el objetivo central del proyecto educacional libertario. Esta formación debía basarse en el aprendizaje de la biología corporal, métodos de higiene y la práctica del ejercicio físico como medios para canalizar la energía sexual acumulada que permitirían al niño y adolescente abordar su futura vida erótica sin traumas ni problemas ${ }^{19}$.

La postura favorable al desarrollo de una educación sexual en la infancia no era exclusiva del anarquismo, sino que se encontraba directamente influida por la labor de propagandistas y médicos del movimiento pro-reforma sexual español, entre los que destacan especialmente César Juarros, José Sanchís Banús o Gonzalo Rodríguez Lafora, entre otros. Desde el campo médico, e inspirados en la aportación del psicoanálisis a la pedagogía sexual infantil, estos médicos, sexólogos y psiquiatras defendieron activamente la aplicación de una disciplina que había surgido con fuerza a finales del siglo XIX. La aceptación de que el menor poseía sexualidad propia, a pesar de no tener todavía madurez genital, lo sitúa como colectivo prioritario para acabar con la lacra de la procreación «inconsciente» ${ }^{20}$.

La educación sexual debía comprender varias fases y a distintos actores. El contacto inicial del niño con la sexualidad recaería en los padres, quienes previamente debían haberse capacitado para fomentar en sus hijos una mirada limpia del cuerpo. La entrada del menor en la escuela marcaría el siguiente momento en esta escala formativa a la que se sumaba, sin desaparecer los progenitores, el maestro. En una segunda fase, el niño debía adquirir el conocimiento necesario respecto a la reproducción, la fecundación y la higiene para una vivencia natural y libre de su propia sexualidad. También se alertaba al menor de los riesgos que conllevaba el incumplimiento de estas reglas y los peligros que acarrearía para su salud prácticas sexuales precoces y dañinas como el onanismo. Finalmente, la última etapa coincidiría con el periodo de la adolescencia en el que se debía aprender todo lo relacionado con el erotismo y la psicología sexual para poder forjar una relación sentimental y sexual

18 Estudios, 77, enero de 1930.

19 Acracia, 307, 19 de julio de 1937. Estudios, 95, julio de 1931; 143, julio de 1935. Vía Libre, $31,1^{\circ}$ de mayo de 1937.

20 DEL CURA y HUERTAS, 64/218 (Madrid, 2004): 987-1002. LÁZARO LORENTE, 1996: 109-119. HUERTAS y NOVELLA, 764 (Madrid, 2013): 1-9. 
sin prejuicios. Según Mariano Gallardo — seguidor de las ideas amorosas de Émile Armand-, su éxito futuro dependía de consolidar su práctica como única vía posible para alcanzar la liberación sexual, ya que dejarla a la espontaneidad, la apatía o la subjetividad de cada uno sería abocarla al fracaso ${ }^{21}$.

Las críticas desde la propia prensa confederal sobre la falta de un comportamiento moral hacia el sexo, evidencia que los comportamientos tradicionales interiorizados desde la infancia eran difíciles de erradicar en la edad adulta. En febrero de 1938, Hombres Libres, órgano de la Federación Provincial cenetista en Granada, acusaba a los jóvenes de mantener una actitud pasiva hacia el sexo impidiendo un cambio en las estructuras mentales colectivas, por seguir comportándose tal y como mandaba la tradición: «Todos quieren ser libres, pero pocos se capacitan ${ }^{22}$. La necesidad de aclarar conceptualmente todo lo relacionado con lo sexual se inserta en que la práctica cotidiana muestra la pervivencia de una sexualidad fuertemente masculinizada en el seno de la organización sindical. Muchos libertarios interpretan la libertad sexual en clave egoísta al no aceptar que una mujer sexualmente libre pudiera rehusar el ofrecimiento masculino al contacto sexual, siendo tildada por éstos de estar sexualmente reprimida. Pero no todo era inacción o falta de interés por modificar el comportamiento aprehendido, ya que las continuas peticiones de asesoramiento sobre aspectos sexuales en los distintos consultorios médicos muestran la ignorancia general de una población ávida por adquirir nuevos conocimientos ${ }^{23}$.

\section{Los debates doctrinales en la prensa anarquista de los años treinta: ¿pro- creación o anticoncepcionismo?}

La defensa desde la prensa anarquista de una mirada «biologicista» de la sexualidad lleva el surgimiento de un discurso de separación entre amor - ligado al sentimiento-, y sexo - relacionado con el cuerpo-, considerados dos conceptos separados pero complementarios que generan, a su vez, dos corrientes distintas en la interpretación moralista de la sexualidad. Por un lado, una vía revolucionaria basada en la masa obrera como poder colectivo

21 Brazo y Cerebro, 18, 1 de febrero de 1936. Estudios, 160, enero de 1937.

22 Hombres Libres, 58, 4 de febrero de 1938.

23 Uno de estos lectores del consultorio de Roberto Remartínez confundía, en 1933, los espermatozoides con «microbios», mientras otro preguntaba si una mujer podía evitar quedarse encinta bebiendo únicamente un vaso de agua después del coito. El éxito de este formato de consulta denota que, a pesar del desconocimiento general, existía una formidable curiosidad y preocupación por aprender cuestiones básicas para la salud individual. Estudios, 86, octubre de 1930. Butlletí CNT-FAI, 4, 23 de enero de 1937. Estudios, 119, julio de 1933. BERENGUER, 1984: 75. 
para la construcción de una nueva sociedad y, por otro, un modelo de exaltación de la libertad individual y búsqueda de bienestar personal. La importancia de lo natural como principio rector del comportamiento sexual conduce a privilegiar el acto de la procreación como el objetivo final de todo contacto erótico. Las concomitancias con el concepto de procreación en la moral burguesa son evidentes, aunque se diferencian en que la posición que ocupa dios es sustituida por la naturaleza. El sacramento del matrimonio es reemplazado por la noción de que la finalidad biológica de la pareja, como cualquier especie animal, es la generación de la vida como parte de la ley natural ${ }^{24}$.

En esta línea, el amor es para Federico Urales un artificio de la naturaleza para conseguir que el hombre se reproduzca, ya que no podía haber mayor acto amoroso que engendrar «un ser que sea nuestra obra y nuestro encanto» ${ }^{25}$. David Díaz defendía también el carácter físico-químico de las relaciones que se englobaban bajo el término «amor» para demostrar que tenía un origen biológico-sexual. Por esta razón, para Urales no podía existir amor «natural» en aquellas parejas que conscientemente practicaran la anticoncepción porque estarían contraviniendo un precepto natural, ya que hombre y mujer debían entregarse «sin tener en cuenta las consecuencias de su conjunción», dejando que la naturaleza siga su curso. En la misma línea que Kropotkin o Réclus, Urales defiende el «natalismo» en contra de las tesis mayoritarias neomalthusianas que abogan por una reducción consciente y notable de la descendencia. Estas teorías comenzaron a difundirse desde comienzos del siglo XX, época de la eclosión de la Liga de Regeneración Humana apoyada por Paul Robin, Luis Bulffi o Pedro Vallina. Esta exaltación del concepto del «reproductivismo» refleja que una de las interpretaciones mayoritarias aboga por la existencia de una forma correcta y otra incorrecta de las relaciones sexuales. Se privilegiaba el instinto genésico a la libre elección individual. Esta visión peyorativa del uso de anticonceptivos o acciones que fomentasen la infertilidad tiene relación, como señala Mary Nash, con que estas prácticas se habían asociado tradicionalmente a las prostitutas. El estigma que rodea su utilización se unía a que la masa obrera era percibida como un factor revolucionario de primera magnitud, de ahí que muchos creyeran que una política tendente a reducir su número perjudicaría el triunfo futuro de una revolución mundial ${ }^{26}$.

Libertarios como Higinio Noja o Antonio Llauradó se mostraron activos defensores de esta visión biologicista del acto sexual: «nuestra vida toda tiene una única misión y motivo: asegurar la continuación del germen mediante la

24 Estudios, 119, julio de 1933. El Sembrador, 10, 25 de octubre de 1930.

25 La Revista Blanca, 102, 15 de agosto de 1927.

26 Estudios, 69, mayo de 1929. La Revista Blanca, 102, 15 de agosto de 1927. NASH, 1981: 49. ESPIGADO TOCINO, 2004: 479. ÁLVAREZ JUNCO, 1991: 296. NASH, 2007: 240. 
reproducción ${ }^{27}$. Javier Serrano y Pilar Grangel conciben el amor como la vía más rápida y placentera para conseguir el éxito del coito, paso previo para el verdadero objetivo que sería el alumbramiento de nueva vida. Para la libertaria valenciana esta era la finalidad última del sentimiento amoroso y, por tanto, el amor era un elemento secundario y sometido al dictado de la especie. Tampoco faltan quienes niegan la importancia del amor en las relaciones humanas señalando que, tras ese sentimiento, sólo se encuentra la necesidad fisiológica de perpetuar la especie, tal como subrayaba Augusto M. Alcrudo. La labor divulgativa adopta formas educacionales concretas que evidencian el desconocimiento general en biología humana, de ahí que Alfredo Royo Lloris explique en sus artículos en qué consisten las fases de la reproducción y los órganos sexuales, mientras Roberto Remartínez informa sobre los periodos más prolíficos para que el ayuntamiento carnal derive en una concepción exitosa. Con ese propósito, se recomendaba tomar las máximas precauciones posibles: el hombre no debería procrear antes de los 25 años y la mujer sólo entre los 20 y los 35 años y únicamente debería ser practicada por hombres y mujeres físicamente sanos y robustos, para evitar que en caso de contraer alguna enfermedad aumentara el riesgo de que naciera una descendencia débil o deficiente. Son consejos que buscan reducir riesgos para la salud de los progenitores, especialmente de las mujeres, dados los altos índices de mortalidad en el momento del parto y el puerperio ${ }^{28}$.

Frente a la corriente natalista, otros libertarios iban a argumentar desde tesis neomalthusianas y eugenistas que «la cópula no tiene por única finalidad la reproducción de la especie» ${ }^{29}$, sino que supera las barreras biológicas para dar satisfacción a apetencias sentimentales y orgánicas que también deben ser valoradas. La separación de la procreación del sexo permite la asunción de la idea de la maternidad consciente como una necesidad indudable de las mujeres. Esto les permitiría asumir el control sobre su propio cuerpo y la decisión acerca del momento en que querían quedarse encinta, desterrando la casualidad y la ignorancia por la premeditación y la libre elección. El bienestar del individuo se antepone a otras cuestiones, al entenderse que es dueño directo de su futuro, frente a políticas maximalistas que someterían su bienestar individual al grupal y agudizarían la depauperación de las familias obreras y el desgaste físico de las mujeres.

Uno de sus principales defensores fue Isaac Puente, para el que se trataba de un derecho intrínseco del individuo que evitaría el nacimiento de personas

27 Estudios, 119, julio de 1933.

28 Estudios, 66, febrero de 1929; 81, mayo de 1930; 111, noviembre de 1932; 113, enero de 1933; 144, agosto de 1935. El Libertario, 62, 1 de abril de 1933. Iniciales, 9, septiembre de 1934. Brazo y Cerebro, 26, 15 de junio de 1936.

29 Estudios, 91, marzo de 1931. 
con enfermedades o taras degenerativas que supusieran un lastre para sus familias. Así se conseguiría, en su opinión, proteger la salud de la madre y evitar fallecimientos prematuros por agotamiento, consecuencia de un elevado número de partos. La reducción consciente del número de miembros que componían las familias pretendía poner remedio a la miseria social y evitar que una descendencia excesiva fuera sinónimo de pobreza, paro y prostitución. Su difusión posibilitaría un aumento de la capacidad adquisitiva de las familias, una disminución de los conflictos armados y un aumento del nivel cultural de la población que permitiría la difusión del pacifismo. Ideas similares albergaban Floreal del Campo o Mariano Gallardo, para quienes el neomalthusianismo no necesitaba ser defendido porque la realidad social justificaba por sí sola su adopción como único mecanismo posible para evitar la degeneración social ${ }^{30}$.

La apuesta por el sentimiento amoroso frente al «natalismo» no perseguía el rechazo del segundo, sino el respeto del primero. Para Isaac Puente, amor y sexo son dos elementos complementarios que únicamente podían coexistir cuando se dieran las condiciones necesarias que permitieran a las personas decidir libremente. Si bien algunos propagandistas abogaban por evitar el contacto sexual para eludir la contracción de enfermedades, otros, como el médico aragonés Augusto M. Alcrudo, consideraban que no se podía impedir a dos personas que se amaban abstenerse del sexo únicamente por el riesgo a la transmisión de alguna dolencia, de ahí que abogara especialmente en estos casos por el uso de los métodos anticonceptivos. La apuesta por la contracepción se realizaba desde la óptica neomalthusiana y a partir de sus obras de referencia, reeditadas en la década de los años treinta y vendidas en la prensa libertaria, y cuya lectura se aconsejaba para adquirir conciencia y un mayor conocimiento sobre la materia: Huelga de vientres. Medios prácticos para evitar las familias numerosas (1906) del médico español Luis Bulffi; Generación consciente del francés Frank Sutor; Medios prácticos para evitar el embarazo del también francés Gabriel Giroud (alias Dr. Hardy); y La educación sexual (1910) de Gaston Havard (alias Jean Marestán) ${ }^{31}$.

La confluencia de generaciones distintas con interpretaciones diversas hacía que, a pesar de los juicios a favor o en contra de la reproducción y la anticoncepción, ambas corrientes convivieran dentro de un movimiento que respetaba la diversidad. Un ejemplo de esta coexistencia lo ofrece la ponencia sobre el concepto confederal del comunismo libertario, en el apartado referido a la

30 Estudios, 132, agosto de 1934. Iniciales, 1 al 5, enero-mayo de 1935. Brazo y Cerebro, 5, 15 de julio de 1935. El Porvenir del Obrero, 1, 2 de enero de 1932. ACKELSBERG, 1999: 63. CLEMINSON, 2008. ÁlVAREZ PELÁEZ, 1995: 29-40; 2004: 59-76. NAVARRO NAVARRO, 1997: 32-105. BARRACHINA, 64/218 (Madrid, 2004): 1003-1026.

31 Estudios, 100, diciembre de 1931; 103, marzo de 1932. NAVARRO NAVARRO, 1997: 89-96. 
sexualidad, presentada en el Congreso de Zaragoza de 1936. Alejandro Gilabert, Francisco Tomás y Nemesio Galve, en representación del Sindicato de la Construcción de Barcelona, plantearían la necesidad de respetar por encima de todo la libertad personal: «El individuo, hombre o mujer, tiene derecho a practicar la libre experimentación amorosa, procreando o evitando la procreación, según la voluntad de las parejas humanas» ${ }^{32}$. El principal interés del anarquismo era mostrar que, a pesar de tratarse de temas privados que competían al individuo, eran decisiones que afectaban a la colectividad en su conjunto:

Pensad en la gravedad de las consecuencias que entraña el hecho de procrear. No tratéis ese hecho a la ligera. Reflexionad en su enorme importancia por lo que toca a vosotros mismos, a vuestros hijos, al hijo por venir y a la sociedad de que sois miembros. Por consiguiente, no más hijos inesperados, no deseados; no más hijos cuya temida llegada sería tenida por vosotros por una especie de desgracia, casi de catástrofe ${ }^{33}$.

A través de las preguntas a los distintos consultorios se evidencia que el desconocimiento general sobre los métodos contraceptivos no sólo era escaso, sino que las opciones relativas a la práctica sexual se reducían a arriesgarse a contraer alguna enfermedad venérea o a la castidad. Los diferentes estudios sobre anticoncepción en la España de finales del siglo XIX y principios del XX muestran el escaso conocimiento que existía de las prácticas cotidianas de las familias españolas. Esta realidad se unía a la dificultad existente para comprar productos profilácticos en una sociedad que catalogaba dichas prácticas como inmorales y antirreligiosas. Revistas como Estudios o Iniciales intentaron paliar esta realidad con la venta de estos artículos a través de sus páginas. El elevado número de consultas hizo necesario respuestas colectivas que aclararan cuestiones que se repetían habitualmente. M. Casado, lector de La Revista Blanca, pregunta en 1935 si el uso del condón es perjudicial para la salud, mientras en 1936 «Un grupo de entusiastas» quería saber, como ejemplo de la ignorancia general sobre estos temas, si el uso de anticonceptivos podía ser perjudicial para la mujer que fuera virgen. Había también quienes, como Germinal Pei, evitan todo contacto sexual ante el miedo a las enfermedades venéreas, actitud que revela la existencia profunda de tópicos y malentendidos así como la ignorancia sobre los citados productos ${ }^{34}$.

Médicos y publicaciones libertarias, además de recomendar el uso puntual o habitual de estos procedimientos, llevaron a cabo también una campaña de

32 Solidaridad, 44, 25 de abril de 1936.

33 Estudios, 142, junio de 1935.

34 La Revista Blanca, 270, 23 de marzo de 1934; suplemento al no 219, 17 de agosto de 1934; 322, 22 de marzo de 1935. Estudios, 158, noviembre de 1936. GUEREÑA, 64/218 (Madrid, 2004): 869-896. TERRÓN BAÑUELOS, 1990. IGNACIUK, 2009: 365-370. 
difusión e información de los distintos productos y métodos anticonceptivos, quedando reducido a cuatro tipologías: físiológicos, mecánicos, químicos y quirúrgicos.

En los métodos fisiológicos, aunque el coitus interruptus es el más común junto a la lactancia prolongada, era generalmente despreciado por ineficaz y pernicioso para la salud, tanto del hombre como de la mujer. La condena de la Iglesia Católica de la contracepción no impedía el ejercicio silencioso y secreto de medios que perseguían la reducción del número de nacimientos; sin embargo, el desdén hacia su extensión tiene su explicación en los estudios médicos que desde mediados del siglo XIX habían mostrado los efectos negativos que tenía para el individuo la no consumación completa del acto sexual. La lista de las posibles dolencias era amplia e incluía trastornos psíquicos, neurosis sexual y afecciones genitales, por lo que muchas de ellas fueron englobadas bajo el término histeria y, como señala la etimología de la palabra, achacadas a la mujer por ser afecciones físicas y mentales sin causa orgánica. Mejor consideración tenían aquellos procedimientos que se servían de la esterilidad fisiológica de la mujer para evitar su embarazo, como el método Ogino-Knaus. Su utilización, apoyada porque no dañaba con productos químicos el organismo y respetaba la cópula natural, fue defendida por anarquistas como Roberto Remartínez o Amparo Poch y Gascón, que crearía el llamado grupo Ogino para la divulgación de dicho sistema anticonceptivo. Otros como Félix Martí Ibáñez desconfiaban de su efectividad y del hecho de que no hubiera sido condenado por la Iglesia católica. Tal era el enfrentamiento moral entre una y otra ideología que se desconfiaba de un método aprobado por la religión, duramente criticada por su conservadurismo, por el riesgo a las comparaciones ${ }^{35}$.

Sin embargo, de todos sus defensores, el más activo fue nuevamente Isaac Puente. El médico vasco intentaba que el conocimiento contraceptivo sirviera a las mujeres en su vida sexual diaria, enseñando cómo elaborar de forma correcta un calendario con los días del ciclo menstrual. Se trataba de un método relativamente novedoso porque, a pesar de haber sido desarrollado en 1924 por el ginecólogo Kyusaku Ogino, fue perfeccionado en 1928 por el médico Hermann Knaus. Sería este último el que divulgaría Puente a través de Estudios, pretendiendo demostrar su viabilidad con la realización de una encuesta entre sus lectores. La petición, que consiguió movilizar en mayo de 1936 hasta un total de 50 testimonios, le lleva a deducir que no sólo se trata de un método eficaz, sino bien acogido socialmente por permitir las relaciones sexuales sin el uso de productos artificiales. En los casos demostrados de equivocación, Puente lo achaca, más que a un fallo del método, a un error de

35 NASH, 2 (Valencia, 1988): 22. GUEREÑA, 64/218 (Madrid, 2014): 870. GALLEGO, 1976: 15. RODRIGO, 2002: 78. Estudios, 142, junio de 1935; 136, diciembre de 1934. 
algunas mujeres en la confección del mismo al no poder señalar con exactitud la fecha de sus próximas reglas ${ }^{36}$.

FIGURA II. Calendario del método Ogino-Knauss basado en los 28 días del ciclo menstrual elaborado por Isaac Puente para la revista Estudios

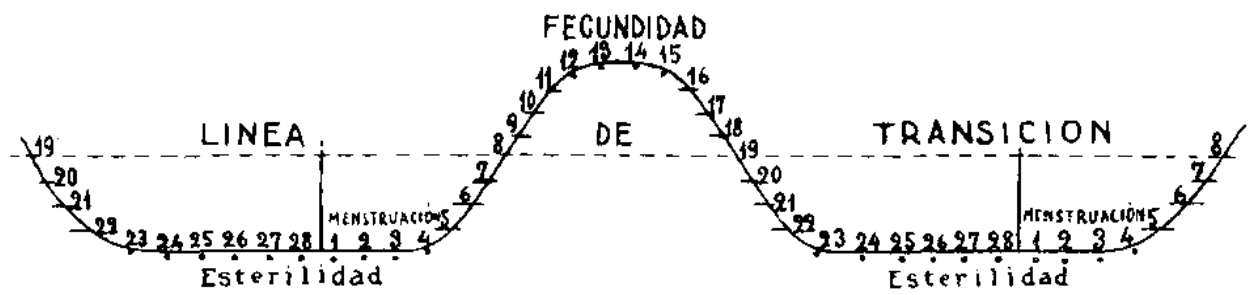

Fuente: Estudios, 154, junio de 1936.

Los métodos mecánicos eran los más eficaces y ventajosos. Los propagandistas, conscientes de la diversidad de público al que se dirigen, aconsejan uno u otro en función del tipo de relación sexual. A las mujeres se les recomiendan generalmente los pesarios, obstáculos de plata que impiden la entrada del líquido seminal en la matriz. Para Puente son los más adecuados para las parejas que tengan relaciones sexuales de forma periódica, tanto por la ausencia de molestias en la mujer como por su fácil limpieza y colocación. Dada la existencia de varias marcas comerciales, el más recomendable es el pesario «Tarnkappe» frente al modelo «Securitas» por ser más efectivo y sencillo. Mientras, las revistas Estudios e Iniciales aconsejan y venden el tipo «Fermita» bajo el titular: «iMujer! Tu felicidad conyugal está en tus manos». Roberto Remartínez, aunque admite su índice de éxito, señala que su inconveniente estriba en saber colocarlos correctamente por lo que debían utilizarse de forma excepcional. En el caso del hombre, los profilácticos se aconsejan para las relaciones sexuales circunstanciales y en las que exista riesgo de contagio venéreo. El preservativo se convierte durante esta época en uno de los medios anticonceptivos más extendidos en España, a pesar de que nunca llegó a ser un método totalmente seguro para luchar contra las enfermedades de transmisión sexual. Puente no aconseja su empleo cotidiano porque tienen un índice de riesgo bastante elevado, mientras Remartínez, que lo califica como el anticonceptivo perfecto en caso de no romperse, y Javier Serrano, son partidarios de su uso por ser la fórmula más recomendable para cohabitar y no

36 Estudios, 140, abril de 1935; 144, agosto de 1935; 146, octubre de 1935; 149, enero de 1936; 151, marzo de 1936; 154, junio de 1936. 
procrear. Las revistas también ofrecían una enorme oferta profiláctica destinada a extender su utilización. Los había de dos tipos: los más económicos, por ser de un solo uso; y los de precio más elevado y lavables, generalmente marcas extranjeras como «Latex», «Neverrip», «Liebefet», «Oriental», «Velo» o «Argento», realizados en un material más resistente y reutilizable. La utilización de uno u otro, salvada las posibles reticencias morales a su empleo, dependía principalmente de la capacidad económica de la pareja o del trabajador, lo que en buena medida dificultaba aún más su extensión ${ }^{37}$.

Otro de los métodos recomendados eran las irrigaciones químicas o preparados domésticos, como óvulos o conos con propiedades espermicidas, no sólo por salud, sino también para mejorar el bienestar físico. Para Roberto Remartínez son los mejores medios para evitar la concepción conforme a un uso racional y consciente, aunque advierte que no son absolutamente fiables. Entre los productos aconsejados están los comprimidos «Semorí», la pomada «Patentex», o los conos eugénicos «Azcon». Isaac Puente señala que Semorí y Patentex, ambos de origen alemán, están especialmente indicados para relaciones sexuales accidentales y con riesgo de contagio venéreo, de ahí que sean habituales los avisos sobre los riesgos para la salud de su uso continuado. En el caso de la pomada, Puente señala que era comercializada por el Instituto de Sexología de Berlín dirigido por Magnus Hirschfeld, lo que aumentaba la confianza del médico vasco hacia un producto del que no era totalmente partidario. Durante la guerra, la revista del Comité Ejecutivo de Espectáculos Públicos de Valencia, Semáforo, los anunciaba dirigiéndose directamente a la mujer con el eslogan «asegura tu felicidad» ${ }^{38}$.

Pero su elevado precio (en torno a 6 pesetas) y la necesidad de utilizar productos complementarios para conseguir un correcto funcionamiento - como el irrigador obturador que valía 11'50 ptas. y el espéculo que costaba en torno a 21 ptas. - impedía la extensión de un consumo generalizado entre las familias obreras. Junto a los preparados se recomendaban espermicidas de preparación doméstica como solución de permanganato potásico, solución de formol, solución de cloramina o vinagre, agua acidulada con vinagre, agua oxigenada diluida, agua formolada, etc. Las obras de referencia en la materia sirven también de base para recomendar fórmulas «caseras», de ahí que se aconsejen también los preparados recomendados por G. Hardy en Medios para evitar el

37 Estudios, 87, noviembre de 1930; 103, marzo de 1932; 116, abril de 1933; 134, octubre de 1934; 142, junio de 1935; 152, abril de 1936. Iniciales, 2, febrero de 1934; 9, septiembre de 1934; 11, noviembre de 1935; La Revista Blanca, 319, 1 de marzo de 1935; 322, 22 de marzo de 1935. GUEREÑA, 64/218 (Madrid, 2004): 871-891. CASTEJÓN BOLEA, 64/218 (Madrid, 2004): 941-945.

38 Estudios, 87, noviembre de 1930; 91, marzo de 1931; 103, marzo de 1932; 111, noviembre de 1932. Semáforo, 1, 1 de noviembre de 1936. 
embarazo. Javier Serrano - a través de otro de sus seudónimos, el de Dr. Fantasma-, indica los distintos compuestos y las cantidades exactas que habría que utilizar en una fórmula diseñada por él mismo. Durante el conflicto bélico se observa un aumento de los anuncios y recomendaciones de productos anticonceptivos, ante el riesgo del aumento de enfermedades sexuales entre los milicianos y soldados, poniendo en riesgo el frente de guerra ${ }^{39}$.

Por último, los procedimientos de carácter quirúrgico como la vasectomía (hombre/mujer) o el aborto (mujer) son los que mayor discusión y oposición generaron dentro de las filas ácratas, a pesar de ser prácticas extraordinarias y únicamente recomendadas en caso de absoluta necesidad. Como señala Xavier Díez, el debate generaba controversias dentro del anarquismo individualista, más sensible hacia la defensa de los derechos individuales y la libertad personal sobre el bien del colectivo. Para Roberto Remartínez y Javier Serrano la esterilización o castración atenta contra el carácter generatriz de la naturaleza impidiendo al hombre o a la mujer ser padres en un futuro. Su uso se descartaba por el carácter irreversible de la operación y porque existían otros procedimientos menos peligrosos y eficaces, a lo que se unía el hecho de que levantaba reticencias porque había sido utilizado por varios Estados - como Alemania o EEUU-, como mecanismo de regulación poblacional contra sus ciudadanos. En el fondo, se aprecia la persistencia de una concepción clásica del ser en el que sexo y género se interrelacionan inexorablemente como elementos constitutivos de lo que se entiende por hombre y mujer. Las principales reticencias se sustentan en fundamentos morales que afectarían, en el caso del hombre, a su carácter viril poniendo en duda su propia masculinidad ${ }^{40}$.

Ante la oposición con la que se estaba encontrando la difusión de la vasectomía en los círculos libertarios, Federica Montseny, en nombre de La Revista Blanca, le pediría a Isaac Puente en 1935 que explicara los pros y los contras de dicha operación. Aquella petición no sólo le situaba como uno de sus máximos defensores en España, sino que evidencia la relevancia que había adoptado el tema dentro del mundo cultural libertario. Para justificar su defensa, Puente señalaba que se trataba de una práctica favorecida por la Liga Internacional para la Prevención de la Repoblación — ligada a la AIT_, por lo que, no solo contaba con el auspicio de destacadas personalidades del anarquismo internacional como Sebastian Faure, sino que su utilización se complementaba perfectamente con la defensa de la libertad del individuo para

39 Iniciales, 6, junio de 1935. Estudios, 136, diciembre de 1934; 145, septiembre de 1935. Semáforo, 1, 1 de noviembre de 1936; 17, 15 de noviembre de 1937.

40 Estudios, 119, julio de 1933. DÍEZ, 21 (Italia, 2002): 121. ÁLVAREZ PELÁEZ, 1995: 29-40. VILLAREJO GALENDE, 23/2 (Barcelona, 2008): 126-135. CASTILLEJO CUÉLLAR, 26 (Bogotá, 2007): 126-137. MINNA STERN, $2 / 2$ (Buenos Aires, 2006): 173-190. 
disponer a su antojo de su cuerpo ${ }^{41}$. En cuanto al argumentario propiamente médico, y teniendo en cuenta las críticas recibidas especialmente por su irreversibilidad, el médico vasco argumenta que, en el fondo, se trata de dos prácticas distintas. Por un lado, la vasectomía, que sería irreparable, y, por otro, la «vasotomía», que permitiría la recuperación parcial de la potencia fecundadora del hombre en un futuro. Aunque actualmente la segunda se trata de una técnica no utilizada por su escasa fiabilidad, el hecho de que las mencione se debe a que la primera se encontraba demasiado relacionada con la prácticas esterilizadoras impulsadas por el régimen nazi contra aquellos individuos que padecían alguna tara física o psíquica y no quería que esto se asociara con el anarquismo. Para Puente, tanto la vasectomía como la vasotomía eran procedimientos extraordinarios, eficaces y seguros desde un punto de vista médico, especialmente para el varón, dado que su porcentaje de error era casi inexistente. En cambio, en el caso de la mujer, descartaba totalmente su utilización por los graves riesgos que conllevaba cualquier tipo de operación en el vientre ${ }^{42}$.

El otro medio quirúrgico contraceptivo por excelencia sería el aborto que ya, desde principios de siglo, se había convertido en motivo de controversia tanto desde perspectivas médicas y sanitarias como religiosas y morales. El principal inconveniente con el que se encontraban los defensores de su práctica era su ilegalidad y persecución - ya que seguía vigente el Código Civil de 1889 - En mayo de 1935, un juzgado de Madrid decretaba prisión incondicional sin fianza para una matrona acusada de un delito de aborto. Las reformas implementadas por la nueva constitución republicana, progresistas en muchos aspectos, no incluían temas conflictivos como el de la prostitución o la interrupción voluntaria del embarazo. Esta realidad aumentaba las reticencias hacia su extensión debido a que la clandestinidad no sólo encarecía su coste, sino que aumentaba exponencialmente el riesgo de la mujer a padecer graves problemas para su salud. A esto se le unía la condena pública de la moral católica dominante que la consideraba poco ética y pecaminosa, culpando a sus practicantes de cometer homicidio. Razón por la cual, en 1931, se iba a crear la Sección de Matronas de la CNT, una forma de conseguir cierta protección sindical ${ }^{43}$.

El papel de los propagandistas se iba a circunscribir a la denuncia del aborto clandestino por los enormes riesgos que conllevaba para la mujer y alertar del peligro que suponía el uso de las fórmulas tradicionales para interrumpir el embarazo. Contusiones en el vientre, ingestión de venenos, uso de bujías,

41 La Revista Blanca, 333, 7 de julio de 1935; 362, 27 de diciembre de 1935.

42 La Revista Blanca, 333, 7 de julio de 1935; 362, 27 de diciembre de 1935. Estudios, 118, junio de 1933; 142, junio de 1935.

43 NASH, 2 (Valencia, 1988): 19-20. FALCÓN O’NEILL, 2009: 213-220. RUIZBERDÚN y GOMIS BLANCO, 2017: 82-90. 
sondas de caucho o irrigaciones intrauterinas de agua jabonosa o formol eran algunas de los métodos que más se utilizaban en esta época. Medidas desesperadas que tomaban muchas mujeres con embarazos no deseados ante el miedo al estigma social, tanto por parte de la sociedad como de sus propias familias. Médicos como Javier Serrano o Roberto Remartínez alertan de la gravedad de la puesta en práctica de dichos remedios que solían acabar en infecciones y hemorragias conducentes, por lo general, al fallecimiento de la mujer. La obsesión recurrente en las consultas de los periódicos y los artículos era la necesidad de instruir a la mujer sobre los peligros del aborto clandestino. Fuera del mundo médico, anarquistas como Camillo Berneri, contextualizaban la problemática del aborto señalando a los Estados como los principales culpables de la situación al implementar políticas natalistas sin preocuparse por solucionar cuestiones como la pobreza y la escasez de recursos alimenticios de muchas familias ${ }^{44}$.

La realidad evidenciaba que, a pesar de la condena legal, la penalización de su práctica y la falta de medios, el aborto clandestino era una práctica habitual en la sociedad española. La falta de una educación sexual sin tabúes que difundiera la necesidad de utilizar medios anticonceptivos pre-gestación, con la consiguiente reducción del número de abortos, influía directamente en la vivencia y experimentación con miedo y desconocimiento de la sexualidad propia. Esta situación se agudizaba especialmente en el caso de las mujeres, incluso las anarquistas, que tenían muchas reticencias a experimentar el amor libre ante el riesgo evidente de un embarazo no deseado y sus consecuencias. Este fue el caso de Concha Pérez Collado, libertaria afiliada a la CNT desde 1931, que llegó a desarrollar aversión a las relaciones sexuales y, por ende, a los hombres, ante el miedo de quedarse embarazada y verse sometida a la exclusión que acompañaba a las mujeres solteras sin recursos y con hijos ${ }^{45}$.

La novela de temática social de Francisco Caro Crespo, Luz en las tinieblas, muestra el caso de una joven hermosa y cándida que, violada por el administrador de su padre, tuvo que deshacerse del bebé para salvar el honor de su casa. Su salvación vendría merced a un hombre, símbolo del obrero consciente, que entiende que el único culpable de su sufrimiento es la injusta sociedad encarnada en personajes identificados con la burguesía. Libertarios como Galo Díez - miembro del Comité Nacional cenetista durante la Guerra Civil—, alertan también a las mujeres del riesgo que asumen uniéndose con hombres de mentalidad tradicional, y aconsejando uniones entre hombres y mujeres de probada virtud anarquista ${ }^{46}$ :

44 El Porvenir del Obrero, 1, 2 de enero de 1932. Solidaridad Obrera, 837, 12 de abril de 1934. Estudios, 96, agosto de 1931; 105, mayo de 1932.

45 NASH, 2007: 236. MORONI, 5 (s.1., 2008): 100.

46 CARO CRESPO, s.d.: 31. Acracia, 301, 12 de julio de 1937. 
Desgraciada de ella si obedeciendo los impulsos de su naturaleza joven y ansiosa de goces, o si en un momento de entusiasmo amoroso no pone resistencia a los excitantes deseos carnales del novio que, a cambio de conseguirla, le promete fidelidad y cariño eterno, y quede embarazada y luego abandonada y soltera. ¡Desgraciada de ella! ${ }^{47}$

No existe tampoco una posición única acerca de la interrupción consciente y voluntaria de la gravidez. Remartínez es más favorable al uso de medidas previas como los anticonceptivos que eviten la necesidad del aborto, mientras para Fausto Brand, en consonancia con esa visión natalista ya aludida, es una práctica ajena al ideal libertario: "Todo ser engendrado tiene derecho a la vida. Privarle de él, sobre todo por sus propios padres, constituye un crimen de lesa humanidad que no se puede purgar ni con la misma vida» ${ }^{48}$. Esta explicación no es exclusiva del movimiento libertario que, inconscientemente, se aproxima a la interpretación católica del aborto. Ambas percepciones refrendan el carácter de crimen que constituye su praxis, para unos por ir contra las leyes de la naturaleza y para otros contra Dios. Al igual que sucediera con los anticonceptivos, el elevado número de consultas realizadas sobre el aborto lleva a realizar una respuesta colectiva. Roberto Remartínez desde Estudios y Javier Serrano desde La Revista Blanca aconsejan que toda intervención de interrupción del embarazo sea realizada por un especialista, ya que de lo contrario existían demasiados riesgos para la salud de la embarazada ${ }^{49}$.

Entre los defensores de su práctica, Puente sostiene una visión más ideológica que medicinal, al no centrarse en los riesgos e inconvenientes del aborto, sino en analizarlo desde un punto de vista moral. Desde esta óptica, se trata de una herramienta fundamental para la emancipación sexual de la mujer y la mejora de la sociedad: "Para nosotros la tesis del aborto es esta: reconocimiento del derecho de la mujer a hacer abortar siempre que ella lo quiera. $\mathrm{Su}$ cuerpo es suyo» ${ }^{50}$. El riesgo para la mujer estaba en su carácter clandestino que le impedía disponer de medios adecuados y profesionales cualificados que realizaran la operación sin peligro. Se abogaba por su legalización y la necesidad de establecer su carácter gratuito para velar por su salud y convertirla en una práctica viable en el futuro. Por esta razón, José Pardo Babarro critica su penalización al tratarse de un derecho inexorable de la mujer y señalando las posibles causas que pueden conducir a una mujer a abortar: de índole médico (enfermedad), moral (deshonra social) o económico (pobreza) ${ }^{51}$.

47 DÍEZ, 1922: 17.

48 Solidaridad Obrera, 112, 4 de marzo de 1933.

49 Estudios, 134, octubre de 1934. La Revista Blanca, 270, 23 de marzo de 1934.

50 Estudios, 105, mayo de 1932.

51 Brazo y cerebro, 19, 15 de febrero de 1936. 
Más que posturas determinadas sobre temas concretos, existen interpretaciones individuales que alcanzan mayor o menor predicamento en función de la visibilidad alcanzada por su defensor. Esta situación se hace especialmente evidente tras el estallido de la Guerra Civil, en la que la CNT y la FAI mutan de fuerzas de oposición al Estado republicano en partes constituyentes del mismo. Las instituciones son utilizadas para ejecutar el ideario revolucionario, pero la aplicación de leyes impulsadas por los anarquistas no son consecuencia de un debate interno dentro del movimiento sino que se deben a las motivaciones y pensamiento de determinados individuos que ocupan los puestos de decisión. El 25 de diciembre de 1936, siendo el faísta Pedro Herrera consejero de Sanidad y Asistencia Social de Cataluña y Federica Montseny la ministra homónima del gobierno central, se promulga el decreto que regula oficialmente la interrupción del embarazo. Con la aprobación de la ley, triunfaba la corriente eugénica que defendía el aborto como una conquista revolucionaria que debía conducir a la emancipación integral de la mujer. Cabeceras como Solidaridad Obrera de Barcelona, convertido en vocero oficial del anarquismo estatista, interpretaba el decreto como un triunfo de los trabajadores. Conseguido el marco legal, la «Soli» confiaba en que sólo quedaba para su definitivo éxito que la mujer lo hiciera suyo ${ }^{52}$.

La «reforma eugénica del aborto» contemplaba hasta cuatro supuestos que permitían a la mujer abortar: causas terapéuticas, motivos eugénicos, neomalthusianismo y circunstancias sentimentales o éticas. El decreto imponía que sólo podría practicarse en hospitales o clínicas dependientes de la Generalitat catalana y por un personal previamente seleccionado que reuniera las capacidades técnicas necesarias. Su regulación establecía que antes de someterse a la interrupción de su embarazo tenía que completar una ficha médica estandarizada que debía albergar información psicológica, eugénica y social de la solicitante. Además debía pasar un reconocimiento médico obligatorio para valorar su estado de salud, prohibiéndose que pudiera realizar más de un aborto al año para salvaguardar su salud. La legalización de la interrupción voluntaria del embarazo pretendía, según Martí Ibáñez, disminuir el número

52 Solidaridad Obrera, 1483, 13 de enero de 1937. El decreto firmado por Pedro Herrera había sido confeccionado por un consejo técnico profesional dirigido por Martí Ibáñez. Dicho organismo tenía la misión de asesorar e informar sobre los problemas que pudieran surgir, así como estudiar y elaborar nuevos decretos para abordar los siguientes aspectos: organización hospitalaria y sanatorial; organización médica; escuelas de medicina y profesiones sanitarias; inspección médico-escolar; asistencia social; higiene del trabajo y medicina social; farmacia; veterinaria; hidrología médica; propaganda sanitaria; lucha antivenérea, antituberculosa, psiquiátrica y antileprosa y reforma eugénica (dentro de la que se incluía la legalización del aborto). Una vez que el reglamento en cuestión era redactado por el consejo, se le remitía al consejero que debía dar obligatoriamente su aprobación para su definitiva implementación. Solidaridad Obrera, 1534, 13 de marzo de 1937; 1567, 21 de abril de 1937. 
de abortos y promover la creación de centros educativos para la difusión de los anticonceptivos. Al mismo tiempo que se recurría a la fuerza policial y judicial para garantizar la aplicación del decreto y en caso de mala praxis se perseguía criminalmente a los culpables y se ordenaba la expulsión de los profesionales médicos intervinientes ${ }^{53}$.

El 30 de abril de 1937, el Diari Oficial de la Generalitat de Catalunya publicaba una circular firmada por Martí Ibáñez en la que se recordaba a los médicos que no cumpliesen la normativa vigente que sufrirían las máximas sanciones posibles, lo que demuestra que el decreto no se estaba cumpliendo o se intuía que no se iba a cumplir. Sin embargo, la salida de los anarquistas del gobierno catalán y el posterior desarrollo de la guerra impedirían aplicar todas las reformas y decisiones adoptadas por los distintos consejeros de Sanidad ligados a la CNT-FAI. Durante el tiempo de aplicación del decreto, 1937 y 1938, se realizaron un total de 281 operaciones de forma legal, de forma que el alcance de la legislación abortiva fue mínimo y un fracaso en términos generales. El aborto, a pesar de los intentos por normalizar su práctica, quedó inserto dentro de las redes tradicionales de la clandestinidad y la ocultación. El carácter impositivo de la norma, la falta de tiempo para su correcta difusión y no haber contado con el apoyo o asesoramiento de organizaciones como Mujeres Libres impidió que el nuevo marco legal permeara en el subconsciente femenino ${ }^{54}$.

El anarquismo español, en opinión de Richard Cleminson, supo generar sus propios discursos en materia sexual en un ambiente cultural que aceptaba la diversidad conceptual como parte indisoluble de la propia ideología. La guerra permitió al anarquismo adquirir una posición de preeminencia, principalmente en Cataluña, a partir de la que intentar los cambios requeridos por la moral sexual. En poco menos de un año se pretendió impulsar la reforma del sistema sanitario catalán con la reorganización de hospitales y asilos; la creación de liberatorios de prostitución y consultorios juveniles de orientación sexual; y la erección de un instituto de Ciencias sexuales similar al edificado por Magnus Hirschfeld en Berlín para la investigación y enseñanza de la eugenesia y la sexología. Salvo el decreto de legalización del aborto, las circunstancias impidieron la puesta en práctica de las disposiciones proyectadas, pero es evidente que la falta de consenso interno acerca de las características de la reforma sexual evidencia que no se trató de una prioridad. Una parte del

53 Diari Oficial de la Generalitat de Catalunya, 9, 9 de enero de 1937. Solidaridad Obrera, 1485, 15 de enero de 1937. Estudios, 160, enero de 1937. NASH, 2007: 238-246.

54 Diari Oficial de la Generalitat de Catalunya, 123, 3 de mayo de 1937. Solidaridad Obrera, 1482, 12 de enero de 1937. Vía Libre, 30, 24 de abril de 1937. Los datos se refieren al Hospital de la Santa Cruz y de San Pablo de Barcelona. La documentación relativa al Hospital Clínico desapareció por lo que la cifra ofrecida es aproximada. NASH, 2 (Valencia, 1988): $32-35$. 
movimiento libertario, especialmente después de transcurridos los primeros meses del conflicto, defendían que la implantación de estas medidas debía posponerse al triunfo en la guerra dada la imposibilidad de su aplicación real. Sin embargo, esta perspectiva resulta ilusoria por la atomización existente en el bando leal a la República, imposibilitando que en tiempos de paz se hubieran podido aplicar dichos preceptos sin oposición. A pesar de todo, el hecho de que militantes como Carmen Quintana, afiliada a las JJLL, encuentren espacios en la prensa para denunciar situaciones machistas y la necesidad de moralizar el comportamiento demuestra el posicionamiento de los órganos oficiales confederales en favor de una nueva forma de sentir lo íntimo ${ }^{55}$.

\section{CONCLUSIONES}

El presente trabajo muestra la contradicción entre el pensamiento filosófico anarquista en materia sexual y la práctica cotidiana de un movimiento que no supo darse cuenta, como señalara Pierre Bordieu ${ }^{56}$, de que el pensamiento presente del obrero estaba mediatizado por su herencia cultural y, por ende, no era libre en su actuación. Esta falta de libertad impedía la extensión de una vivencia real de los presupuestos teóricos de una militancia demasiado absorbida por la idea de que la revolución debía ser principalmente política para instaurar una sociedad sin clases ni Estado. Sin embargo, para buena parte de lo que podemos considerar como «aristocracia militante», el anarquismo no sólo representaba la revolución en la calle y las barricadas, sino especialmente un ideal moral en el que la labor pedagógica para la modificación de la percepción y las prácticas sexuales de los militantes era fundamental para el futuro revolucionario.

La sexualidad es interpretada como un mecanismo más para la eliminación del autoritarismo que se entiende es intrínseco al orden establecido y a la moral sexual tradicional. Anarquistas como Higinio Noja, Martí Ibáñez o Isaac Puente recurrían a estudios médicos y sexuales de destacados médicos y sexólogos nacionales e internacionales para ofrecer una visión lo más rigurosa posible de la sexualidad. La originalidad ácrata reside, a pesar de no haber generado un discurso propio, en adaptar las concepciones médicas de destacados médicos y sexólogos, tanto europeos como españoles, a su concepción particular del hombre y la mujer. La crítica del matrimonio burgués y la prostitución tiene su correlato en la defensa de una naturalización del sexo como parte indisoluble de una moral sexual que se basa en una visión del cuerpo a partir de postulados naturistas que contemplan el desnudo como la manifesta-

55 Estudios, 160, enero de 1937. Faro, 7, 24 de diciembre de 1937. CLEMINSON, 2008: 13. NASH, 1981: 26 y 43; 2007: 214.

56 BOURDIEU y CHARTIER, 2011: 43. 
ción de la belleza natural, y no desde un prisma de lujuria o pornografía. Esto conduce a la condena de la virginidad y la castidad como valores que atentan contra las leyes de la naturaleza.

La prensa libertaria, especialmente publicaciones como Estudios o $\mathrm{La} \mathrm{Re}$ vista Blanca, se convirtió en un importante canal de difusión de estas ideas. Mediante los consultorios médicos, habituales en estas revistas, se establecía un diálogo directo entre emisor y receptor en el que se respondían a dudas y problemas cotidianos de una población analfabeta lastrada por la ausencia de una educación sexual desde la infancia. Sin embargo, esta moral sexual ácrata no se trataba de un todo uniforme y perfectamente definido, sino que en su seno convivían corrientes diferenciadas acerca de cómo debía canalizarse la práctica sexual. Por un lado, estaban los defensores del sexo como mecanismo para la propagación de la especie y don natural al que no deben ponérsele cortapisas ni límites porque sería ir contra el fundamento principal de la naturaleza, la constante continuación de la vida. Idea de raigambre decimonónica que consideraba que la reducción de la población, lo que los anarquistas entienden por «masa obrera», reducía sustancialmente la potencialidad revolucionaria y hacía peligrar el triunfo futuro de la revolución. Y, por otro, aquellos que separaban la idea de la procreación del sexo y abogaban por el uso consciente y médico de los anticonceptivos para limitar así el crecimiento incontrolado de una población que, según planteamientos neomalthusianos muy vigentes entonces, hacía peligrar el futuro de la raza humana. La separación de la procreación del sexo permitía también la asunción de la idea de la maternidad consciente como una necesidad de los seres emancipados, mientras la anticoncepción es reivindicada como arma al servicio de la clase obrera para contrarrestar los «males» de la sociedad burguesa (guerras, población excesiva, paro forzoso, etc.).

Los procedimientos contraceptivos que más debate generaron fueron aquellos medios quirúrgicos de carácter permanente — vasectomía y aborto-, por el miedo que en algunos sectores ácratas suponía perder la capacidad generatriz de hombres y mujeres, ya que para muchos era acabar con su finalidad como especie. Sin embargo, el fondo del debate se centraba en que si la mujer debía tener o no el derecho a decidir sobre su propio cuerpo, en cualquier situación y circunstancia. Sus defensores abogaban por la necesidad de su legalización, criticando la penalización de lo que consideraban era un derecho inexorable de la mujer. Y aunque se trataba de una demanda que muchos defensores de la reforma sexual pedían desde sus escaños y consultas, la realidad socio-política de España durante la Segunda República impidió la puesta en práctica de este tipo de reformas, demasiado progresistas para muchos sectores.

La Guerra Civil y el vuelco social que propició la llegada de la CNT-FAI al poder en regiones como Cataluña permitiría la asombrosa aplicación de la 
llamada «reforma eugénica del aborto» con Federica Montseny como ministra de Sanidad. Esto supuso el triunfo definitivo de la corriente ácrata que abogaba por el control de la natalidad, sin embargo, el decreto promulgado por la Generalitat de Cataluña, a pesar de que regulaba la práctica abortiva dentro de la legalidad institucional, fue poco aplicado durante los meses que estuvo en vigor. Esto se debería, en buena medida, a la pérdida de la influencia cenetista tanto en el gobierno como en la calle en beneficio del partido comunista. La labor impulsada por la consejería de Sanidad del gobierno catalán, aún en manos de la CNT/FAI, no consiguió realmente concienciar sobre los beneficios de su práctica dentro de un orden regulado. Cuestión que no se debía a la falta de mujeres que quisieran abortar, sino porque seguía dominando la misma moral que licenciaba este tipo de comportamientos de forma pública. Resulta paradigmático el hecho de que fueran militantes de la CNT y la FAI, desde las estructuras de un Estado que durante los años de la República habían combatido, los que hicieran posible, en la medida de sus posibilidades y en medio del conflicto bélico, llevar a la práctica algunas de las medidas defendidas por el reformismo médico de aquellos años.

\section{BibLIOGRAFÍA}

Ackelsberg, Martha, Mujeres Libres. El anarquismo y la lucha por la emancipación de las mujeres, Barcelona, Virus editorial, 1999.

Álvarez Junco, José, La ideología política del anarquismo español, Madrid, Siglo Veintiuno de España, 1991.

Álvarez Peláez, Raquel, «Eugenesia y darwinismo social en el pensamiento anarquista», en Bert Hofmann, Pere Joan i Tous y Manfred Tielz (coords.), El Anarquismo español y sus tradiciones culturales, Frankfurt/Main, Vervuert/Iberoamericana, 1995: 29-40.

Álvarez Peláez, Raquel, «Félix Martí Ibáñez y la eugenesia en España», en José Vicente Martí y Antonio Rey Hazas (coords.), Actas del I Simposium Internacional Félix Martí Ibáñez: Medicina, historia e ideología, Valencia, Generalitat Valenciana, 2004: 59-76.

Álvarez Peláez, Raquel, «Publicaciones sobre sexualidad en la España del primer tercio del siglo XX: entre la medicina y la pornografia», Hispania. Revista Espanola de Historia, 64/218 (Madrid, 2004): 947-960.

Andrés Granel, Helena, «Anarquismo y sexualidad», Germinal: revista de estudios libertarios, 5 (s.1., 2008): 65-84.

Aresti, Nerea, Médicos, donjuanes y mujeres modernas. Los ideales de feminidad y masculinidad en el primer tercio del siglo XX, Bilbao, Universidad del País Vasco, 2001. 
Aresti, Nerea, Masculinidades en tela de juicio: hombres y género en el primer tercio del siglo XX, Madrid, Ediciones Cátedra, 2010.

Barrachina, Marie Aline, «Maternidad, feminidad, sexualidad. Algunos aspectos de las primeras jornadas eugénicas española (Madrid, 1928 - Madrid, 1933)», Hispania. Revista Española de Historia, 64/218 (Madrid, 2004): 1003-1026.

Berenguer, Sara, Entre el sol y la tormenta: treinta y dos meses de guerra (19361939), Barcelona, Seuba, 1984.

Bourdieu, Pierre y Chartier, Roger, El sociólogo y el historiador, Madrid, Abada, 2011.

Caro Crespo, Francisco, Luz en las tinieblas, Barcelona, Col. La Novela Ideal, s.d.

Castejón Bolea, Ramón, «Las estrategias preventivas individuales en la lucha antivenérea: sexualidad y enfermedades venéreas en la España del primer tercio del siglo XX», Hispania. Revista Española de Historia, 64/218 (Madrid, 2004): 923-946.

Castillejo Cuéllar, Alejandro, «Raza, alteridad y exclusión en Alemania durante la década de 1920», Revistas de Estudios Sociales, 26 (Bogotá, 2007): 126-137.

Cleminson, Richard, Anarquismo y sexualidad en España (1900-1939), Cádiz, Publicaciones de la Universidad de Cádiz, 2008.

De Villena, Luis Antonio, Héroes, atletas, amantes. Historia esencial del desnudo masculino, Barcelona, Ed. Península, 2008.

Del Cura, Mercedes y Huertas García-Alejo, Rafael, «Medicina y sexualidad infantil en la España de los años treinta. La aportación del psicoanálisis a la pedagogía sexual», Hispania. Revista Española de Historia, 64/218 (Madrid, 2004): 987-1002.

Díez, Galo, La mujer en la lucha social, Avellaneda, Ed. Centro de Caninillitas, 1922.

Díez, Xavier, Utopía sexual a la premsa anarquista de Catalunya: la revista ÉticaIniciales (1927-1937), Barcelona, Pagès editors, 2001.

Díez, Xavier, «Amaos y no os multipliquéis. El discurso ético-sexual del anarquismo individualista en Cataluña (1927-1937)», Spagna contemporánea, 21 (Italia, 2002): 99-124.

Espigado Tocino, María Gloria, «Las mujeres en el anarquismo español (18691939», Ayer, 45 (Madrid, 2002): 39-72.

Espigado Tocino, María Gloria, «Amor y deseo en los medios anarquistas. "La Victoria” de Federica Montseny», en María Gloria Espigado Tocino, María José de la Pascua Sánchez y María del Rosario García-Doncel Hernández (coords.), Mujer y deseo: representaciones y prácticas de vida, Cádiz, Servicio de Publicaciones de la Universidad de Cádiz, 2004: 467-484.

Falcón O’Neill, Lidia, «Las mujeres en la República», en Julio Rodríguez Puértolas (coord.), La República y la cultura: Paz, guerra y exilio, Madrid, Ediciones Istmo, 2009: 213-220.

Gabriel Fernández, Narciso de, «Alfabetización, semialfabetización y analfabetismo en España (1860-1991)», Revista Complutense de Educación, 8/1 (Madrid, 1997): 199-232.

Gallego García, Gregorio, En las garras de la lujuria, Barcelona, Ed. La Revista Blanca, 1936.

Gallego García, Gregorio, Madrid corazón que se desangra, Madrid, Ed. G. del Toro, 1976. 
García Maroto, María de los Ángeles, La mujer en la prensa anarquista, Madrid, Fundación Anselmo Lorenzo, 1996.

Gracia Cárcamo, Juan, «Microsociología e historia de lo cotidiano», Ayer, 19 (Madrid, 1995): 189-222.

Guereña, Jean-Louis, «Elementos para una historia del preservativo en la España contemporánea», Hispania. Revista Española de Historia, 64/218 (Madrid, 2004): 869-896.

Guereña, Jean-Louis (coord.), La sexualidad en la España Contemporánea (18001950), Cádiz, Servicio de Publicaciones de la Universidad de Cádiz, 2011.

Huertas, Rafael y Novella Gaya, Enric, «Sexo y modernidad en la España de la Segunda República. Los discursos de la ciencia», Arbor: ciencia, pensamiento y cultura, 764 (Madrid, 2013): 1-9.

Ignaciuk, Agata, «Anticoncepción, aborto y género: aportaciones desde los estudios en la historia y las ciencias sociales», en María Elena Jaime de Pablos (coord.), Identidades femeninas en un mundo plural, Almería, Arcibel editores, 2009: 365-370.

Lázaro Lorente, Luis M., «El debate acerca de la educación sexual en la España de los años treinta», en El currículum: historia de una mediación social y cultural / IX Coloquio de Historia de la Educación, Granada, 23-26 de septiembre de 1996, Granada, Universidad de Granada, 1996: 109-119.

Lora Medina, Alejandro, «La vivencia del ideal anarquista en la España de los años treinta», Hispania Nova, 16 (Madrid, 2018): 134-163.

Lorenzo Pinar, Francisco Javier, La familia en la historia, Salamanca, Ediciones Universidad de Salamanca, 2009.

Méndez Pérez, Lourdes, Cuerpos sexuados y ficciones identitarias. Ideologías sexuales, deconstrucciones feministas y artes visuales, Sevilla, Instituto Andaluz de la Mujer, 2004.

Minna Stern, Alexandra, «Esterilizadas en nombre de la salud pública: raza, inmigración y control reproductivo en California en el siglo XX», Salud Colectiva, 2/2 (Buenos Aires, 2006): 173-190.

Moreno Mengíbar, Andrés y Vázquez García, Francisco, «Genealogía de la educación sexual en España: de la pedagogía ilustrada a la crisis del estado del bienestar», Revista de Educación, 309 (Madrid, 1996): 67-94.

Moroni, Sara, «Concha Pérez Collado: anarquista, miliciana en la Guerra Civil española», Germinal: revista de estudios libertarios, 5 (s.1., 2008): 99-114.

Nash, Mary, Mujer y movimiento obrero en España, 1931-1939, Barcelona, Editorial Fontamara, 1981.

Nash, Mary, «Género, cambio social y la problemática del aborto», Historia social, 2 (Valencia, 1988): 19-36.

Nash, Mary, «La reforma sexual en el anarquismo español», en Pere Joan Bert Hofmann i Manfred Tielz Tous (coords.), El Anarquismo español y sus tradiciones culturales, Frankfurt/Main, Vervuert/Iberoamericana, 1995: 281-296.

Nash, Mary, Rojas. Las mujeres republicanas en la Guerra Civil, Madrid, Taurus, 2007. 
Navarro Navarro, Francisco Javier, El paraíso de la razón: la revista «Estudios» (1928-1937) y el mundo cultural anarquista, Valencia, Edicions Alfons el Magnànim, 1997.

Navarro Navarro, Francisco Javier, «Sexualidad, reproducción y cultura obrera revolucionaria en España: La revista Orto (1932-1934)», Arbor: ciencia, pensamiento y cultura, 769 (Madrid, 2014): 1-13.

Nead, Lynda, El desnudo femenino: arte, obscenidad y sexualidad, Madrid, Tecnos, 2013.

Pando Despierto, Juan, «Desnudar el asombro. Cuerpo y mente de feminidad en el arte», Espacio, tiempo y forma. Serie VII, historia del arte, 8 (Madrid, 1995): 333-354.

Rodrigo, Antonina, Una mujer libre. Amparo Poch y Gascón, médica anarquista, Barcelona, Flor del Viento Ediciones, 2002.

Ruiz-Berdún, Dolores y Gomis Blanco, Alberto, Compromiso social y género. La historia de las matronas en España en la Segunda República, la Guerra Civil y la Autarquía (1931-1955), Madrid, Ayuntamiento de Alcalá de Henares, 2017.

Sánchez López, Juan Antonio, «Del ideal atlético al ideal heroico. Algunas controversias (pre y post) barrocas sobre el cuerpo», en Carmen González Román y Antonio Bonet Correa (coords.), A través de la mirada. Anatomía, arquitectura y perspectiva en la tradición artística occidental, Madrid, Abada, 2014: 81-126.

Siguán Boehmer, Marisa y Marco, Joaquín, Literatura popular libertaria. Trece años de «la novela ideal» (1925-1938), Barcelona, Península, 1981.

Stern, Alexandra Minna, «Esterilizadas en nombre de la salud pública: raza, inmigración y control reproductivo en California en el siglo XX», Salud colectiva, 2/2 (Argentina, 2006): 173-190.

Terrón Bañuelos, Aída, «Anticoncepción y maternidad consciente en el pensamiento eugenista», en Mujer y educación en España, 1868-1975: VI Coloquio de Historia de la Educación, Santiago de Compostela, Universidade de Santiago, 1990: 327-332.

Vázquez García, Francisco, «Historia de la sexualidad en España: problemas metodológicos y estado de la cuestión», Hispania. Revista Española de Historia, 56/194 (Madrid, 1996): 1007-1035.

Vázquez García, Francisco y Moreno Mengíbar, Andrés, Sexo y razón: una genealogía de la moral sexual en España (siglos XVI-XX), Madrid, Akal, 1997.

Villarejo Galende, Alberto, «Los neurocientíficos en el Tercer Reich», Neurología: publicación oficial de la Sociedad Española de Neurología, 23/2 (Barcelona, 2008): 126-135.

Recibido: 07/06/2017

Aceptado: 23/02/2018

Hispania, 2018, vol. LXXVIII, $\mathrm{n}^{\circ}$. 260, septiembre-diciembre, págs. 817-846, ISSN: 0018-2141, e-ISSN: 1988-8368 https://doi.org/10.3989/hispania.2018.020 